\author{
Chiyoko Hakuta ${ }^{1}$, Ayako Okada ${ }^{2}$, Kaoru \\ Sogabe $^{2}$, Erika Kakuta ${ }^{3}$, Keiko Endo ${ }^{4}$, \\ Susumu Imai ${ }^{2}$, Masaaki Okamoto ${ }^{2}$, \\ Yoshiaki Nomura ${ }^{2}$ and Nobuhiro \\ Hanada $^{2 \star}$ \\ ${ }^{1}$ Preventive Oral Health Care Science, Department \\ of School of Dentistry, Tokyo Medical and Dental \\ University, Tokyo, Japan \\ ${ }^{2}$ Department of Translational Research, Tsurumi \\ University School of Dental Medicine, Yokohama, \\ Japan \\ ${ }^{3}$ Department of Oral Microbiology, Tsurumi \\ University School of Dental Medicine, Yokohama, \\ Japan \\ ${ }^{4}$ Oral Preventive Oral Health Care Science, \\ Department of School of Dentistry, Tokyo Medical \\ and Dental University, Tokyo, Japan \\ Dates: Received: 20 April, 2016; Accepted: 02 May, \\ 2016; Published: 04 May, 2016 \\ ${ }^{*}$ Corresponding author: Dr. Nobuhiro Hanada, \\ D.D.S, Ph.D, Department of Translational Research \\ Tsurumi University School of Dental Medicine, 2-1-3 \\ Tsurumi, Tsurumi-ku, Yokohama 230-8501, Japan, Tel: \\ (+81) 45-580-8462; Fax: (+81) 45-573-2473; E-mail: \\ hanada-n@tsurumi-u.ac.jp \\ www.peertechz.com
}

ISSN: 2455-4634

Keywords: Opportunistic pathogens; Oral care; Oral hygiene and sampling

\author{
Research Article
}

\section{Opportunistic Bacteria in Tonsil and Dental Plaque are Indicator for Oral}

\section{Care}

\begin{abstract}
Background of the study: Detection of the opportunistic microorganisms can be the indicator for the oral hygiene. However, there are many sampling sites in one subject.

Context and purpose of study: The purpose of this study was to evaluate the suitable sampling site for opportunistic pathogens as an indicator of the oral hygiene.

Results: In the 21 healthy females' swab samples of tonsil, meticillin-sensitive Staphylococcus aureus, Pneumobacillus, Haemophilus influenzae, H. parainfluenzae, Lancefield group A streptococci, Lancefield group G streptococci, Haemophilus sp. were detected; detection rates were $33.3 \%, 4.8 \%$, $19.0 \%, 4.8 \%, 4.8 \%$ and $14.3 \%$, respectively. The detection rates of methicillin-sensitive Staphylococcus aureus and Haemophilus sp. were the highest when compared to the other sampling sites. For $\mathrm{H}$. influenzae, the detection rates were relatively high; $14.3 \%$ for tongue, $38.1 \%$ for dental plaque and $52.4 \%$ for saliva.
\end{abstract}

Main findings: Detections of the commensal and opportunistic pathogens from tonsil and saliva were independent. Microbial flora form nasal cavity was independent form pharynx.

Conclusion: Tonsil and saliva are the suitable sampling site to detect the opportunistic pathogens for the indicator of the oral hygiene.

Brief Summary: Opportunistic pathogens in tonsil or saliva can be the indicator of the oral hygiene.

Potential implications of the study: For the prevention of pneumonia, oral care is useful. In this situation, MRSA, $P$. aeruginosa, $\beta$-hemolytic streptococci, $S$. marcescens, $M$. catarrhallis or $H$. influenza in tonsil or saliva can be the indicator of the oral care.

\section{Abbreviations}

S. aureus: Staphylococcus aureus; MSSA: Methicillin Sensitive Staphylococcus aureus; MRSA: Methicillin-Resistant Staphylococcus aureus; H. influenzae: Haemophilus influenza; S. marcensencs: Serratia marcescencs; $P$. aeruginosa: Pseudomonas aeruginosa; $M$. catarrhalis: Moraxella catarrhalis; H. parainfluenzae: Haemophilus parainfluenzae; Hib: Haemophilus influenzae type b; CNS: CoagulaseNegative Staphylococci;

\section{Introduction}

Opportunistic pathogens have been known to be detected form saliva, dental plaque, and tonsil [1-3]. These pathogens of itself are not pathogenic for the healthy subjects, however, these pathogens cause serious status for the immunocompromised patients or elderly subjects.

Opportunistic pathogens can be the indicator for the oral hygiene status. Opportunistic microorganisms are not commensal bacteria. Dental plaque is a kind of biofilm on the tooth surface that is composed of glucans [4] and many kinds of non-commensal bacteria colonize and grow on matured dental plaque. Thus, dental plaque is also known to be a reservoir for cross-infection by opportunistic pathogens [5]. Dental plaque can be removed by the oral cares. In addition, the intensive oral cares reduce the pneumonia and respiratory infections through the reductions of oropharyngeal bacteria especially in elderly bed-bound nursing home patients [69]. Thus, detection of the opportunistic microorganisms can be the indicator for the oral hygiene. However, there are many sampling sites in one subject. Therefore, in this study, we tried to identify the representative sampling site of the opportunistic pathogens as indicator of oral hygiene.

Several kinds of opportunistic bacteria inhabit in upper respiratory tract [10], therefore, it is generally considered that nasal cavity is the bacterial reservoir for the pharynx and it is the agents for pharyngitis. Therefore, we additionally checked the co-ration of the bacterial flora (including Candia sp.) from nasal cavity, pharynx and oral cavity.

\section{Materials and Methods}

\section{Subjects and sampling}

Twenty one healthy female students of the dental hygiene school were included in this study. Their mean ages were $22.1 \pm 2.11$. Sampling for all the subjects were carried out within one month. In this study, subjects with, systemically healthy, without periodontitis and dental caries, possessed at least 20 teeth and had not taken systemic antibiotics, anti-inflammatory drugs or immunosuppressive drugs in the 3 month were included for the sampling. Periodontal statutes were evaluated according to the criteria proposed by the Center for Disease 
Table 1: Descriptive analysis of the detections and detection rates of the commensal bacteria and opportunistic bacteria

\begin{tabular}{|c|c|c|c|c|c|c|c|c|c|c|c|c|c|c|c|c|c|c|c|c|c|}
\hline & \multicolumn{3}{|c|}{ Nasal cavity } & \multicolumn{3}{|c|}{ Pharynges } & \multicolumn{3}{|c|}{ Tonsil } & \multicolumn{3}{|c|}{ Bucal Mucosa } & \multicolumn{3}{|c|}{ Tongue } & \multicolumn{4}{|c|}{ Dental Plaque } & \multicolumn{2}{|c|}{ Saliva } \\
\hline & - & + & $\%$ & - & + & $\%$ & - & + & $\%$ & - & + & $\%$ & - & + & $\%$ & - & + & $\%$ & - & + & $\%$ \\
\hline$\alpha$-streptococci & 20 & 1 & 4.8 & 0 & 21 & 100 & 0 & 21 & 100 & 0 & 21 & 100 & 0 & 21 & 100 & 1 & 20 & 95.2 & 0 & 21 & 100 \\
\hline Y-streptococci & 21 & 0 & 0 & 12 & 9 & 42.9 & 16 & 5 & 23.8 & 19 & 2 & 9.5 & 11 & 10 & 47.6 & 17 & 4 & 19.0 & 11 & 10 & 47.6 \\
\hline Neisseria sp. & 21 & 0 & 0 & 4 & 17 & 81.0 & 3 & 18 & 85.7 & 3 & 18 & 85.7 & 0 & 21 & 100 & 3 & 18 & 85.7 & 0 & 21 & 100 \\
\hline CNS & 14 & 7 & 33.3 & 21 & 0 & 0 & 21 & 0 & 0 & 21 & 0 & 0 & 21 & 0 & 0 & 21 & 0 & 0 & 21 & 0 & 0 \\
\hline Enterobacteria & 19 & 2 & 9.5 & 21 & 0 & 0 & 21 & 0 & 0 & 21 & 0 & 0 & 21 & 0 & 0 & 21 & 0 & 0 & 21 & 0 & 0 \\
\hline MSSA & 15 & 6 & 28.6 & 20 & 1 & 4.8 & 14 & 7 & 33.3 & 20 & 1 & 4.8 & 19 & 2 & 9.5 & 19 & 2 & 9.5 & 17 & 4 & 19.0 \\
\hline Corynebactorium sp. & 20 & 1 & 4.8 & 21 & 0 & 0 & 21 & 0 & 0 & 21 & 0 & 0 & 20 & 1 & 4.8 & 20 & 1 & 5 & 21 & 0 & 0 \\
\hline Pneumobacillus & 21 & 0 & 0 & 21 & 0 & 0 & 20 & 1 & 4.8 & 21 & 0 & 0 & 20 & 1 & 4.8 & 21 & 0 & 0 & 21 & 0 & 0 \\
\hline H. parainfluenzae & 21 & 0 & 0 & 19 & 2 & 9.5 & 17 & 4 & 19.0 & 18 & 3 & 14.3 & 18 & 3 & 14.3 & 13 & 8 & 38.1 & 10 & 11 & 52.4 \\
\hline group A streptococci & 21 & 0 & 0 & 20 & 1 & 4.8 & 20 & 1 & 4.8 & 21 & 0 & 0 & 21 & 0 & 0 & 21 & 0 & 0 & 21 & 0 & 0 \\
\hline group G streptococci & 21 & 0 & 0 & 20 & 1 & 4.8 & 20 & 1 & 4.8 & 21 & 0 & 0 & 20 & 1 & 4.8 & 21 & 0 & 0 & 21 & 0 & 0 \\
\hline Haemophilus sp. & 21 & 0 & 0 & 19 & 2 & 9.5 & 18 & 3 & 14.3 & 20 & 1 & 4.8 & 21 & 0 & 0 & 21 & 0 & 0 & 21 & 0 & 0 \\
\hline Candida sp. & 21 & 0 & 0 & 21 & 0 & 0 & 21 & 0 & 0 & 20 & 1 & 4.8 & 21 & 0 & 0 & 20 & 1 & 4.8 & 21 & 0 & 0 \\
\hline
\end{tabular}

MRSA, Pseudomonas aeruginosa, $\beta$-hemolytic Streptococci, S. marcescens, M. catarrhallis were not detected any samples in this study. For $\alpha$-hemolytic streptococci, $\mathrm{Y}$-hemolytic streptococci, Neisseria sp. as commensal bacteria, the detection rates were high levels, especially for $\alpha$-hemolytic streptococci and Neisseria sp.

Control and Prevention in partnership with the American Academy of Periodontology [11]. Swab samples were obtained from these subjects by scrapping the nasal cavity, pharynges, tonsil, buccal mucosa and tongue by sterilized cotton swab (SEEDSWAB No. 1: Eiken Chemical Co., Ltd. [Eiken], Tokyo). Dental plaque was obtained by scrapping the upper molar part of the dentitions. Saliva samples were obtained by the chewing gum base for five minutes. Before sampling, informed consents were obtained from these subjects. This study was approved by the ethical committee of the Tokyo Medical and Dental University (Approval number: $24-79$ and 25-382).

\section{Bacterial culture and characterization test}

All specimens were transferred into $1 \mathrm{~mL}$ of reduced transport fluid medium ( $0.4 \%$ agar, $0.15 \%$ thioglycollate/ phosphate buffered saline) in sterile bottles on ice and processed within one night of collection. The entire samples in tubes were inoculated onto chocolate agar, blood agar, OPA staphylococcus, and drigalski agar plates (Nippon Becton Dickinson Co., Ltd., Tokyo) with an aid of a stick. The plates were incubated in an atmosphere of $5 \% \mathrm{CO}_{2}$ in $\mathrm{H}_{2}$ at $37{ }^{\circ} \mathrm{C}$ for $24-48 \mathrm{~h}$. Representative microbial colonies from each plate were Gram-stained and identified in terms of their characteristic appearance, hemolytic activity, catalase-, and oxidasetest [10]. Colonies of microbes suspected to be those responsible for pneumonia and which were found in a majority of the subjects were suspended in $1 \mathrm{~mL}$ of $0.5 \%$ saline and tested by using diagnosis kits indicated below $[12,13]$.

We identified Staphylococcus aureus by Gram-stain positive, catalase-positive, oxidase-negative cocci grown on the OPA staphylococcus agar plates. Both methicillin sensitive (MSSA) and resistant (MRSA) strains, were analyzed by the PS latex, and MRSA screening plates (Nippon Becton Dickinson); Coagulasenegative staphylococci (CNS) were analyzed by the rabbit plasma coaggregation test. Streptococcus which was Gram-stain positive, catalase-negative, oxidase-positive cocci, was further identified by the API strepto, and VITEK (BioMerieux Vitek Japan, Tokyo). Hemolytic activity of streptococci was determined by the blood agar plates, as category as alpha- (incomplete), beta- (complete) and gamma- (none). Streptococcal Lancefield antigens was further analyzed by the Seroidenstrepto kit (Eiken). Streptococcus pneumoniae was analyzed by the Streptococcus identification disk (Nippon Becton Dickinson). Pseudomonas sp. which was Gran-stain negative glucsenonfermentous rods, was analyzed by the VITEK. Haemophilus influenzae, which was Gran-stain negative bacilli grown on the chocolate agar plate, was analyzed by the Haemophilus ID4 plate (Nippon Becton Dickinson). Serratia marcescens, which was Granstain negative, bacilli grown on the drigalski agar plates was analyzed by the VITEK. Candida sp. was analyzed by using the Candida check (Iatron Laboratories Inc., Tokyo).

\section{Statistical analysis}

Cross tabulations were constructed and Fisher's exact tests were carried out to calculate the $\mathrm{p}$-values. $\mathrm{P}$-values less than 0.05 were considered to be statistically significant. Hierarchical cluster analysis was carried out to calcify the subjects by the bacterial flora. The analysis was carried out by IBM SPSS Statistics ver 19.0 (IBM Tokyo, Japan).

\section{Results}

The results of the descriptive analysis and detection rates of the each opportunistic pathogens were shown in Table 1. For $\alpha$-hemolytic streptococci, $\gamma$-hemolytic streptococci, Neisseria sp. as commensal bacteria, the detection rates were high levels, especially for a-hemolytic streptococci and Neisseria sp.

As opportunistic bacteria, MRSA and Pseudomonas aeruginosa, $\beta$-hemolytic streptococci, S. marcescens, Moraxella catarrhalis were not detected any samples in this study. From the swab samples of tonsil, MSSA, Pneumobacillus, H. influenzae, H. parainfluenzae, Lancefield group A streptococci bacteria, Lancefield group G streptococci bacteria, Haemophilus sp. were detected; detection rates were $33.3 \%, 4.8 \%, 19.0 \%, 4.8 \%, 4.8 \%$ and $14.3 \%$, respectively. Especially, the detection rates of MSSA and Haemophilus sp. were highest when compared to the other sampling sites. For H. influenzae, detection rates were relatively high in the samples of the oral cavity, $14.3 \%$ for tongue, $38.1 \%$ for dental plaque and $52.4 \%$ for saliva. 
By the cross tabulations shown in Table 2, the number of the subjects who were not detected the MSSA in tonsil and other sampling sites were less than $10 \%$ except for the nasal cavity. The same tendencies were observed for the saliva samples. However, the co-relation between tonsil and saliva was not statistically significant. For the results of the H. influenzae shown in Table 3, same tendencies were also observed in both tonsil and saliva samples. The difference of the MSSA and H. influenzae were the detection rates in tonsil and saliva.

We constructed the cross tabulations of the each bacteria by the tonsil and saliva samples. As shown in the Table 4, statistically significant co-relation was not observed. Therefore, we concluded that the detections of the commensal bacteria and opportunistic bacteria from tonsil and saliva were independent.

Meanwhile, it is generally considered that bacterial flora in nasal cavity is the reservoir for the bacterial flora in pharynx and it responsible for the pharyngitis. As shown in Table 5, most of the opportunistic bacteria examined in this study were not detected from nasal cavity, in contrast statistically significant co-relations were

Table 2: Cross tabulations of the MSSA from tonsil (A) or saliva (B) and other sampling site.

\begin{tabular}{|c|c|c|c|c|c|c|c|c|c|}
\hline \multirow{2}{*}{ MSSA } & & \multicolumn{3}{|c|}{ Tonsil } & \multirow{2}{*}{ MSSA } & & \multicolumn{3}{|c|}{ Saliva } \\
\hline & & - & + & $p$-value & & & - & + & $\mathrm{p}$-value \\
\hline \multirow{2}{*}{ Nasal cavity } & - & 10 & 5 & \multirow{2}{*}{1.000} & \multirow{2}{*}{ Nasal cavity } & - & 12 & 3 & \multirow{2}{*}{1.000} \\
\hline & + & 4 & 2 & & & + & 5 & 1 & \\
\hline \multirow{2}{*}{ Pharynges } & - & 13 & 7 & \multirow{2}{*}{1.000} & \multirow{2}{*}{ Pharynges } & - & 16 & 4 & \multirow{2}{*}{1.000} \\
\hline & + & 1 & 0 & & & + & 1 & 0 & \\
\hline \multirow{2}{*}{$\begin{array}{l}\text { Buccal } \\
\text { Mucosa }\end{array}$} & - & 14 & 6 & \multirow{2}{*}{0.333} & \multirow{2}{*}{ Tonsil } & - & 12 & 2 & \multirow{2}{*}{0.574} \\
\hline & + & 0 & 1 & & & + & 5 & 2 & \\
\hline \multirow{2}{*}{ Tongue } & - & 13 & 6 & \multirow{2}{*}{1.000} & \multirow{2}{*}{$\begin{array}{l}\text { Buccal } \\
\text { Mucosa }\end{array}$} & - & 17 & 3 & \multirow{2}{*}{0.190} \\
\hline & + & 1 & 1 & & & + & 0 & 1 & \\
\hline \multirow{2}{*}{ Saliva } & - & 12 & 5 & \multirow{2}{*}{0.574} & \multirow{2}{*}{ Tongue } & - & 17 & 2 & \multirow{2}{*}{0.029} \\
\hline & + & 2 & 2 & & & + & 0 & 2 & \\
\hline \multirow{2}{*}{$\begin{array}{l}\text { Dental } \\
\text { Plaque }\end{array}$} & - & 14 & 5 & \multirow{2}{*}{0.100} & \multirow{2}{*}{$\begin{array}{l}\text { Dental } \\
\text { Plaque }\end{array}$} & - & 17 & 2 & \multirow{2}{*}{0.029} \\
\hline & + & 0 & 2 & & & + & 0 & 2 & \\
\hline
\end{tabular}

For the detection of MSSA in saliva had statistically significant co-relations with that in tongue and dental plaque. Other correlations were not statistically significant.

Table 3: Cross tabulations of the $H$. painfuenzae from tonsil $(A)$ or saliva (B) and other sampling site.

\begin{tabular}{|c|c|c|c|c|c|c|c|c|c|}
\hline \multirow{2}{*}{$\begin{array}{l}\mathrm{H} \text {. } \\
\text { parainfluenzae }\end{array}$} & & \multicolumn{3}{|c|}{ Tonsil } & \multirow{2}{*}{$\begin{array}{l}H . \\
\text { parainfluenzae }\end{array}$} & & \multicolumn{3}{|c|}{ Saliva } \\
\hline & & - & + & $p$-value & & & - & +1 & $p$-value \\
\hline Nasal cavity & - & 17 & 4 & & Nasal cavity & - & 10 & 11 & \\
\hline \multirow{2}{*}{ Pharynges } & - & 15 & 4 & \multirow{2}{*}{1.000} & \multirow{2}{*}{ Pharynges } & - & 9 & 10 & 1.00 \\
\hline & + & 2 & 0 & & & + & 1 & 1 & \\
\hline \multirow{2}{*}{ Buccal Mucosa } & - & 15 & 3 & \multirow{2}{*}{1.000} & \multirow{2}{*}{ Tonsil } & - & 9 & 8 & 0.586 \\
\hline & + & 2 & 1 & & & + & 1 & 3 & \\
\hline \multirow{2}{*}{ Tongue } & - & 14 & 4 & \multirow{2}{*}{0.591} & \multirow{2}{*}{ Buccal Mucosa } & - & 8 & 10 & 0.586 \\
\hline & + & 3 & 0 & & & + & 2 & 1 & \\
\hline \multirow{2}{*}{ Saliva } & - & 9 & 1 & \multirow{2}{*}{0.586} & \multirow{2}{*}{ Tongue } & - & 10 & 8 & 0.214 \\
\hline & + & 8 & 3 & & & + & 0 & 3 & \\
\hline \multirow{2}{*}{ Dental Plaque } & - & 12 & 1 & \multirow{2}{*}{0.253} & \multirow{2}{*}{ Dental Plaque } & - & 10 & 10 & 1.000 \\
\hline & + & 5 & 3 & & & + & 0 & 1 & \\
\hline
\end{tabular}

For the detection of $H$. painfuenzae all the correlations was not statically significant.
Table 4: Cross tabulations of the tonsil and saliva for all the bacteria investigated in this study.

\begin{tabular}{|c|c|c|c|c|c|}
\hline & & & \multicolumn{2}{|c|}{ Saliva } & \multirow[t]{2}{*}{$p$-value } \\
\hline & & & - & + & \\
\hline \multirow[t]{21}{*}{ Tonsil } & a-streptococci & + & 0 & 21 & \\
\hline & \multirow[t]{2}{*}{ Y-streptococci } & - & 10 & 6 & \multirow[t]{2}{*}{$0.14 \mathrm{~s}$} \\
\hline & & + & 1 & 4 & \\
\hline & \multirow[t]{2}{*}{ Neisseria sp. } & - & 3 & 0 & \\
\hline & & + & 18 & 0 & \\
\hline & CNS & - & 0 & 21 & \\
\hline & Enterobacteria & - & 21 & 0 & \\
\hline & MSSA & - & 12 & 2 & \multirow[t]{2}{*}{0.574} \\
\hline & & + & 5 & 2 & \\
\hline & Corynebactorium sp. & - & 21 & 0 & \\
\hline & \multirow[t]{2}{*}{ P. neumobacillus } & - & 20 & 0 & \\
\hline & & + & 1 & 0 & \\
\hline & \multirow[t]{2}{*}{ H. parainfluenzae } & - & 9 & 8 & \multirow[t]{2}{*}{0.586} \\
\hline & & + & 1 & 3 & \\
\hline & \multirow[t]{2}{*}{ group A streptococci } & - & 20 & 0 & \\
\hline & & + & 1 & 0 & \\
\hline & \multirow[t]{2}{*}{ group G streptococci } & - & 20 & 0 & \\
\hline & & + & 1 & 0 & \\
\hline & \multirow[t]{2}{*}{ Haemophilus sp. } & - & 18 & 0 & \\
\hline & & + & 3 & 0 & \\
\hline & Candida sp. & - & 21 & 0 & \\
\hline
\end{tabular}

The detection of opportunistic pathogens investigated in this study had no correlation between saliva and tonsil.

Table 5: Cross tabulations of the detected bacteria form nasal cavity, saliva, dental plaque and pharynx.

\begin{tabular}{|c|c|c|c|c|c|c|c|c|c|c|}
\hline \multirow[b]{2}{*}{ pharynx } & & \multicolumn{3}{|c|}{ Nasal cavity } & \multicolumn{3}{|c|}{ Saliva } & \multicolumn{3}{|c|}{ Dental plaque } \\
\hline & & - & + & $p$-value & - & + & $\mathrm{p}$-value & - & + & $\mathrm{p}$-value \\
\hline$\alpha$-streptococci & + & 20 & 1 & & 0 & 21 & & 1 & 20 & \\
\hline \multirow[t]{2}{*}{ Y-streptococci } & - & 12 & 0 & & 9 & 3 & \multirow[t]{2}{*}{0.030} & 12 & 0 & \multirow[t]{2}{*}{0.021} \\
\hline & + & 9 & 0 & & 2 & 7 & & 5 & 4 & \\
\hline \multirow[t]{2}{*}{ Neisseria sp. } & - & 4 & 0 & & 0 & 4 & & 3 & 1 & \multirow[t]{2}{*}{0.003} \\
\hline & + & 17 & 0 & & 0 & 17 & & 0 & 17 & \\
\hline CNS & - & 14 & 7 & & 21 & 0 & & 21 & 0 & \\
\hline Enterobacteria & - & 19 & 2 & & 21 & 0 & & 21 & 0 & \\
\hline \multirow[t]{2}{*}{ MSSA } & - & 14 & 6 & \multirow[t]{2}{*}{$>0.999$} & 16 & 4 & & 18 & 2 & \multirow[t]{2}{*}{$>0.999$} \\
\hline & + & 1 & 0 & & 1 & 0 & & 1 & 0 & \\
\hline Corynebactorium sp. & - & 20 & 1 & & 21 & 0 & & 20 & 1 & \\
\hline Pneumobacillus & - & 21 & 0 & & 21 & 0 & & 21 & 0 & \\
\hline \multirow[t]{2}{*}{ H. parainfluenzae } & - & 19 & 0 & & 9 & 10 & \multirow[t]{2}{*}{$>0.999$} & 11 & 8 & \\
\hline & + & 2 & 0 & & 1 & 1 & & 2 & 0 & \\
\hline \multirow[t]{2}{*}{ group A streptococci } & - & 20 & 0 & & 20 & 0 & & 20 & 0 & \\
\hline & + & 1 & 0 & & 1 & 0 & & 1 & 0 & \\
\hline \multirow[t]{2}{*}{ group G streptococci } & - & 20 & 0 & & 20 & 0 & & 20 & 0 & \\
\hline & + & 1 & 0 & & 1 & 0 & & 1 & 0 & \\
\hline \multirow[t]{2}{*}{ Haemophilus sp. } & - & 19 & 0 & & 19 & 0 & & 18 & 1 & \multirow[t]{2}{*}{$>0.999$} \\
\hline & + & 2 & 0 & & 2 & 0 & & 2 & 0 & \\
\hline
\end{tabular}

Most of the opportunistic bacteria examined in this study were not detected from nasal cavity, in contrast statistically significant co-relations were observed in detection of $\mathrm{y}$-hemolytic streptococci from pharynx, saliva and dental plaque.

observed in detection of $\gamma$-hemolytic streptococci from pharynx, saliva and dental plaque. In addition, to check the pattern of flora, subjects were classified three groups with cluster analysis by using the detection of opportunistic bacteria from pharynx, nasal cavity, saliva and dental plaque, respectively. The cross tabulation between 
each group and detection of bacteria were shown in Table 6. The corelation of the groups, pharynx and saliva has statistically significant co-relation was observed. In contrast, nasal cavity was completely independent form pharynx (Table 7).

\section{Discussion}

In this study, we used $\alpha$-hemolytic streptococci, $\gamma$-hemolytic streptococci and Neisseria sp. for the commensal bacteria for the oral cavity. For $\alpha$-hemolytic streptococci and Neisseria sp. detected high proportions of samples.astreptococcus and Neisseria sp. were detected from all the samples of saliva. $\gamma$-hemolytic streptococci were detected frequently, but not all the samples.

Table 6: Cross tabulations of the cluster and detected bacteria form pharynx, saliva, and dental plaque.

\begin{tabular}{|c|c|c|c|c|c|c|c|c|c|c|c|c|c|}
\hline \multirow[b]{2}{*}{ Cluster } & & \multicolumn{4}{|c|}{ Pharynges } & \multicolumn{4}{|c|}{ Saliva } & \multicolumn{4}{|c|}{ Dental Plaque } \\
\hline & & 1 & 2 & 3 & $p$-value & 1 & 2 & 3 & $p$-value & 1 & 2 & 3 & $p$-value \\
\hline \multirow[t]{2}{*}{ a-streptococci } & - & 0 & 0 & 0 & & 0 & 0 & 0 & & 0 & 1 & 0 & \multirow[t]{2}{*}{0.048} \\
\hline & + & 18 & 2 & 1 & & 10 & 5 & 6 & & 17 & 0 & 3 & \\
\hline \multirow[t]{2}{*}{ Y-streptococci } & - & 11 & 0 & 1 & \multirow[t]{2}{*}{0.171} & 5 & 0 & 6 & \multirow[t]{2}{*}{0.002} & 16 & 1 & 0 & \multirow[t]{2}{*}{0.003} \\
\hline & + & 7 & 2 & 0 & & 5 & 5 & 0 & & 1 & 0 & 3 & \\
\hline \multirow[t]{2}{*}{ Neisseria sp. } & - & 2 & 2 & 0 & \multirow[t]{2}{*}{0.029} & 10 & 5 & 6 & & 2 & 1 & 0 & \multirow[t]{2}{*}{0.182} \\
\hline & + & 16 & 0 & 1 & & 0 & 0 & 0 & & 15 & 0 & 3 & \\
\hline CNS & - & 18 & 2 & 1 & & 10 & 5 & 6 & & 17 & 1 & 3 & \\
\hline Enterobacteria & + & 18 & 2 & 1 & & 10 & 5 & 6 & & 17 & 1 & 3 & \\
\hline \multirow[t]{2}{*}{ MSSA } & - & 18 & 1 & 1 & \multirow[t]{2}{*}{0.143} & 10 & 2 & 5 & \multirow{2}{*}{0.013} & 16 & 0 & 3 & \multirow[t]{2}{*}{0.110} \\
\hline & + & 0 & 1 & 0 & & 0 & 3 & 1 & & 1 & 1 & 0 & \\
\hline \multirow{2}{*}{$\begin{array}{l}\text { Corynebactorium } \\
\text { sp. }\end{array}$} & - & 18 & 2 & 1 & & 10 & 5 & 6 & & 17 & 1 & 2 & \multirow[t]{2}{*}{0.190} \\
\hline & + & 0 & 0 & 0 & & 0 & 0 & 0 & & 0 & 0 & 1 & \\
\hline Pneumobacillus & - & 18 & 2 & 1 & & 10 & 5 & 6 & & 17 & 1 & 3 & \\
\hline \multirow[t]{2}{*}{ H. parainfluenzae } & - & 16 & 2 & 1 & \multirow{2}{*}{$>0.999$} & 10 & 0 & 0 & \multirow{2}{*}{$<0.001$} & 10 & 0 & 3 & \multirow[t]{2}{*}{0.138} \\
\hline & + & 2 & 0 & 0 & & 0 & 5 & 6 & & 7 & 1 & 0 & \\
\hline \multirow{2}{*}{$\begin{array}{l}\text { group A } \\
\text { streptococci }\end{array}$} & - & 17 & 2 & 1 & \multirow[t]{2}{*}{$>0.999$} & 10 & 5 & 6 & & 17 & 1 & 3 & \\
\hline & + & 1 & 0 & 0 & & 0 & 0 & 0 & & 0 & 0 & 0 & \\
\hline \multirow{2}{*}{$\begin{array}{l}\text { group G } \\
\text { streptococci }\end{array}$} & - & 18 & 2 & 0 & \multirow[t]{2}{*}{0.048} & 10 & 5 & 6 & & 17 & 1 & 3 & \\
\hline & + & 0 & 0 & 1 & & 0 & 0 & 0 & & 0 & 0 & 0 & \\
\hline \multirow[t]{2}{*}{ Haemophilus sp. } & - & 17 & 2 & 0 & 0.100 & 10 & 5 & 6 & & 16 & 1 & 3 & $>0.999$ \\
\hline & + & 1 & 0 & 1 & & 0 & 0 & 0 & & 1 & 0 & 0 & \\
\hline
\end{tabular}

The co-relation of the groups, pharynx and saliva has statistically significant co-relation was observed.

Table 7: Co-relation of the clusters by the bacterial flora from pharynx, nasal cavity, saliva and dental plaque.

\begin{tabular}{|c|c|c|c|c|c|}
\hline \multirow{2}{*}{\multicolumn{2}{|c|}{ Cluster }} & \multicolumn{3}{|c|}{ Pharynges } & \multirow[b]{2}{*}{$p$-value } \\
\hline & & \multirow{2}{*}{\begin{tabular}{|l|}
1 \\
5
\end{tabular}} & \multirow{2}{*}{$\begin{array}{l}2 \\
1\end{array}$} & \multirow{2}{*}{$\begin{array}{l}3 \\
0\end{array}$} & \\
\hline \multirow{3}{*}{ Nasal cavity } & 1 & & & & \multirow{3}{*}{$>0.999$} \\
\hline & 2 & 2 & 0 & 0 & \\
\hline & 3 & 11 & 1 & 1 & \\
\hline \multirow{3}{*}{ Saliva } & 1 & 10 & 0 & 0 & \multirow{3}{*}{0.023} \\
\hline & 2 & 3 & 2 & 0 & \\
\hline & 3 & 5 & 0 & 1 & \\
\hline \multirow{3}{*}{ Dental Plaque } & 1 & 15 & 1 & 1 & \multirow{3}{*}{0.156} \\
\hline & 2 & 0 & 1 & 0 & \\
\hline & 3 & 3 & 0 & 0 & \\
\hline
\end{tabular}

The subjects were classified three groups with cluster analysis by using the detection of opportunistic bacteria from pharynx, nasal cavity, saliva and dental plaque. By the Fisher's exact test, clusters by the bacterial flora form nasal cavity was completely independent form that of pharynx. The detection of opportunistic pathogens in nasal cavity was completely independent form pharynx.
Even though, the subjects investigated in this study were all young and healthy, MSSA were detected from 33.3\% of tonsil samples and H. influenzae were detected from $52.4 \%$ of saliva samples.

$H$. influenzae is a small, nonmotile Gram-stain negative bacterium in the family Pasteurellaceae. H. influenzae are known to be detected from nasopharynx, oropharynx, upper respiratory tract and lower respiratory tract of the healthy subjects [14]. It is present in the $75 \%$ nasopharynx of approximately $75 \%$ of healthy children and adults. It is rarely encountered in the oral cavity. The most common types of invasive disease are pneumonia, occult febrile bacteremia, meningitis, epiglottitis, septic arthritis, cellulitis, otitis media, purulent pericarditis, and other less common infections such as endocarditis, and osteomyelitis. It is usually the non encapsulated strains that are harbored as normal flora, but a minority of healthy individuals (3-7\%) intermittently harbor $H$. influenzae type b (Hib) encapsulated strains in the upper respiratory tract [15-17]. Hib may cause bacteraemia, meningitis, cellulitis, epiglottitis, septic arthritis, pneumonia, pleural or gallbladder empyema, endophthalmitis, urinary tract infection, abscesses, cervical adenitis, glossitis, osteomyelitis and endocarditis. Non-encapsulated $H$. influenzae strains cause mucosal infections, including exacerbations of chronic bronchitis, otitis media, conjunctivitis, sinusitis, bronchitis and pneumonia. The results of this study may be an indication that oral biofilms are reservoirs for these pathogens.

S. aureus are classified by the degree of antibiotic resistance; MRSA and MSSA. S. aureus is a bacterium that commonly colonized on human skin and mucosa without causing any problems. It can also cause disease; folliculitis or abscess in skin, abscesses in spleen, kidney or epidural space and osteomyelitis.

Neisseria, CNS, MSSA and Haemophilus are known to be inhabit human upper respiratory tract and Haemophilus is not inhabit nasal cavity [10]. In this study Neisseria and Haemophilus were not detected form nasal cavity, but detected form oral cavity. Therefore, oral cavity can be bacterial reservoir for the pharynx.

In this study, MRSA, P. aeruginosa, $\beta$-hemolytic streptococci, $S$. marcescens and M. catarrhallis were not detected any samples. However, according to our previous report, even though the frequencies were less than $10 \%$, these bacteria were detected from saliva, tonsil or dental plaque of the healthy elderly subjects ( more than $80 \%)$ or dental plaque of preschool children $(44.7 \%)$ or health care workers $(66.7 \%)[5,12,13]$. If these bacteria were detected, intensive oral care will be necessary. However, there were several limitations in this study: small sample size, only young females were investigated, sample size were not calculated. Final goal of this kind of study is to prevent the pneumonia for elderlies, especially bedridden subjects. For these subjects sampling of itself become burden. Further study is necessary to get the robust conclusion which can apply to the elderlies based on the results of this study.

\section{Conclusion}

Tonsil and saliva may be the suitable sampling site to detect the opportunistic bacteria for the indicator of the oral hygiene. And if MRSA, P. aeruginosa, $\beta$-hemolytic streptococci, S. marcescens, M. 
catarrhallis or H. influenzae were detected, intensive oral care will be necessary.

\section{Acknowledgement}

The study was supported by JSPS KAKENHI Grant Numbers 23593084 and 24593174.

\section{References}

1. Tada A, Hanada N (2010) Opportunistic respiratory pathogens in the ora cavity of the elderly. FEMS Immunol Med Microbiol 60: 1-17.

2. Ogawa T, Ikebe K, Enoki K, Murai S, Maeda Y (2012) Investigation of oral opportunistic pathogens in independent living elderly Japanese. Gerodontology 29: 229-233.

3. Kitada K, de Toledo A, Oho T (2009) Increase in detectable opportunistic bacteria in the oral cavity of orthodontic patients. Int J Dent Hyg 7: 121-125.

4. Costerton JW, Stewart PS, Greenberg EP (1999) Bacterial biofilms: a common cause of persistent infections. Science 284: 1318-1322.

5. Salam MA, Senpuku H, Nomura Y, Matin K, Miyazaki H, et al. (2001) Isolation of opportunistic pathogens in dental plaque, saliva and tonsil samples from elderly. Jpn J Infect Dis 54: 193-195.

6. Ishikawa A, Yoneyama T, Hirota K, Miyake Y, Miyatake K (2008) Professional oral health care reduces the number of oropharyngeal bacteria. J Dent Res 87: 594-598

7. Yoneyama T, Yoshida M, Ohrui T, Mukaiyama H, Okamoto H, et al. (2002) Oral care reduces pneumonia in older patients in nursing homes. Oral Care Working Group. J Am Geriatr Soc 50: 430-433.
8. Yoneyama T, Yoshida M, Matsui T, Sasaki H. (1999) Oral care and pneumonia. Oral Care Working Group. Lancet 354: 515

9. Yoneyama T, Hashimoto K, Fukuda H, Ishida M, Arai H, et al. (1996) Oral hygiene reduces respiratory infections in elderly bed-bound nursing home patients. Arch Gerontol Geriatr 22: 11-19.

10. Jorgensen JH, Pfaller MA (2007) Manual of Clinical Microbiology, Volume 1, 9th edition.

11. Eke PI, Page RC, Wei L, Thornton-Evans G, Genco RJ. (2012) Update of the case definitions for population-based surveillance of periodontitis. J Periodontol 83:1449-1454.

12. Nomura Y, Senpuku H, Tsuge S, Hayashi M, Sasaki A, et al. (2001) Controlling opportunistic pathogens in the oral cavity of preschool children by the use of 3DS. Jpn J Infect Dis 54:199-200.

13. Nomura Y, Takeuchi H, Senpuku H, Ida H, Yoshikawa E, et al. (2002) Survey of dental hygienists and healthcare workers for microorganisms in the oral cavity. J Infect Chemother 8:163-167.

14. Musher DM. (1996) Haemophilus Species: Baron S. Medical Microbiology. Chapter 30. 4th edition.

15. St Geme JW 3rd. (2000) The pathogenesis of nontypable Haemophilus influenzae otitis media. Vaccine 19: 41-50.

16. Moxon ER, Deich RA, Connelly C. (1984) Cloning of chromosomal DNA from Haemophilus influenzae. Its use for studying the expression of type b capsule and virulence. J Clin Invest 73: 298-306.

17. Zwahlen A, Kroll JS, Rubin LG, Moxon ER. (1989) The molecular basis of pathogenicity in Haemophilus influenzae: comparative virulence of genetically-related capsular transformants and correlation with changes at the capsulation locus cap. Microb Pathog 7: 225-235.

Copyright: (c) 2016 Hakuta C, et al. This is an open-access article distributed under the terms of the Creative Commons Attribution License, which permits unrestricted use, distribution, and reproduction in any medium, provided the original author and source are credited. 